\title{
RETRACTION: Increased incidence of cervical cancer in Sweden: Possible link with HPV vaccination
}

\author{
EDITORS, Indian Journal of Medical Ethics
}

The comment "Increased incidence of cervical cancer in Sweden: Possible link with HPV vaccination" (DOI: 10.20529/ IJME.2018.037) was published online in the Indian Journal of Medical Ethics on April 30, 2018 (1). The author gave his name and affiliation as Lars Andersson, department of Physiology and Pharmacology, Karolinska Institutet (KI), Sweden. On May 8, as soon as $\mathrm{KI}$ informed us that no such person worked there, we carried out a correction the same day and the institution's name was removed as affiliation (2).

On inquiry, the author informed us that he had used a pseudonym besides a false affiliation. He later made his identity known to IJME's editor on the promise of strict confidentiality. On verification of his identity, the editor confirmed that (a) the author had the necessary qualifications, expertise and research experience on the subject of the article; and (b) the author did face a credible threat of harm, making it necessary not to be named publicly.

Further we reconfirmed the reviewers' conclusions: that the article used publicly available data with a simple statistical method; made a fair attempt to report a possible association of the increased incidence of carcinoma cervix with HPV vaccination; and suggested more research. We felt that the data and analysis could be scientifically appreciated and critiqued without reference to the author. Therefore, despite the author's unacceptable deception, the editors decided to retain the article having already made a correction to remove the false affiliation.

Following our decision, we received valuable advice from our editorial board and other well-wishers, emphasising that there should be zero tolerance towards the author's deception, irrespective of the content of the paper. While our assessment of the science of the article may be correct, we have concluded that tolerating the author's deception and retaining the article was an error of judgement. We express our deep gratitude to them and have accepted their advice.

Thus, this article is hereby retracted. We will provide a detailed account of this issue, with the nuances involved, in an editorial at a later date.

As editors, we are wary of the extreme ideological divide that views discussions on vaccines as either "pro" or "anti". In low and middle-income countries like India, where early HPV infection and incidence of carcinoma cervix are relatively high, scientific discussion and resolution of issues concerning the HPV vaccine is critical for women receiving it, and for policy making on its introduction in the universal immunisation programme. We hope that the hypothesis of possible harm of vaccinating women previously exposed to HPV is carefully explored in future studies.

Note: Corrected on July 22, 2018.

\section{References}

1. Andersson L. RETRACTED:Increased incidence of cervical cancer in Sweden: Possible link with HPV vaccination. Indian J Med Ethics. Published online on April 30, 2018.DOI: 10.20529/IJME.2018.037. Available from: http://ijme.in/articles/increased-incidence-of-cervical-cancer-in-sweden-possible-linkwith-hpv-vaccination/?galley=html.

2. Editors, Indian Journal of Medical Ethics. Statement on Corrections. Indian J Med Ethics. Published online on May 9, 2018. DOI: 10.20529/IJME.2018.040. Available from: $\mathrm{https}$ ://ijme.in/articles/statement-on-corrections/?galley=html 


\section{Increased incidence of cervical cancer in Sweden: Possible link with HPV vaccination}

\section{LARS ANDERSSON}

\section{Abstract}

The Centre for Cervical Cancer Prevention in Sweden has noted in its annual report a substantial increase in the incidence of invasive cervical cancer, especially during the two years 2014 and 2015. I have sub-grouped the data according to age, using the same statistical database of the National Board of Health and Welfare as used by the authors of the above-mentioned report. The increase in the incidence of cervical cancer was shown to be most prominent among women 20-49 years of age while no apparent increase was observed among women above 50. The FDA has noted in the clinical trials referred to it for marketing approval that women exposed to the human papilloma virus (HPV) prior to vaccination had an increase in premalignant cell changes compared with placebo controls. I discuss the possibility th -1/ vaccination could play a role in the increase in the in cervical cancer by causing instead of preventing cerl. I I c i disease in women previously exposed to HPV. A ti relati hip exists between the start of vaccination and + crease incidence of cervical cancer. The HPV vaccines approveu in 2006 and 2007, respectively and $m \quad g$ gir. ted to be vaccinated during 2012-2013.

\section{Introduction}

The Centre for Cervical $C$ er $F$ ention (NKCx) in Sweden has noted in it al re, $\quad 017$ which includes data upto 2016 al in _ incidence of invasive cervical er, esp ,llv durliry ...e years 2014 and 2015. An English tr. or ase in the incidence of cervical cancer is give ble $1(1,0)$.

The report states, 'ation):

"The age-standardised incidence of invasive cervical cancer in Sweden has increased substantially in the last two years (20\%) and there is a statistically significant increase for the entire period 2005-2015. The incidence in Sweden for 2014-2015 is

\footnotetext{
Author: Lars Andersson (lars.andersson2@outlook.com), Medical scientist. Under the current circumstances where publication of any information critical of vaccines can have serious personal repercussions, the author has chosen to publish under this pseudonym

To cite: Andersson L. Increased incidence of cervical cancer in Sweden: Possible link with HPV vaccination. Indian J Med Ethics. Published online on April 30, 2018 DOI:10.20529/IJME.2018.037.

Manuscript Editor: Sandhya Srinivasan

(c) Indian Journal of Medical Ethics 2018
}

\begin{tabular}{|c|c|c|c|c|c|}
\hline \multicolumn{3}{|c|}{$\begin{array}{l}\text { Age-standardised (according t } \\
2000 \text { ) incidence of invasive cel }\end{array}$} & $\begin{array}{l}\text { stan } \\
\text { cancer }\end{array}$ & \multicolumn{2}{|c|}{$\begin{array}{l}\text { vedish population in } \\
\text { J,000 women) }\end{array}$} \\
\hline County & $\begin{array}{l}2006 \\
-20\end{array}$ & $\begin{array}{r}2010 \\
?\end{array}$ & & $\begin{array}{c}\text { verage } \\
\text { nge } 2005- \\
\angle 015 \text { expressed } \\
\text { as percentage }\end{array}$ & $\begin{array}{l}\text { p value } \\
\text { for trend }\end{array}$ \\
\hline Swede ot & & 9.56 & .49 & 1.7 & 0.03 \\
\hline Stockı. & 11.j & & 10.59 & -0.8 & 0.51 \\
\hline$\overline{\text { Uppsá. }}$ & 11.16 & 14.17 & 16.02 & 3.8 & 0.20 \\
\hline s manlar. & & 12.43 & 10.57 & 2.3 & 0.40 \\
\hline ergötland & & 14.47 & 15.04 & 7.3 & $<0.05$ \\
\hline köping & 5.33 & 8.38 & 11.17 & 6.4 & 0.04 \\
\hline obera & 8.99 & 6.14 & 13.15 & 1.1 & 0.78 \\
\hline n & 12.78 & 7.39 & 11.83 & -2.4 & 0.50 \\
\hline Gotland & 8.00 & 6.47 & 14.18 & 6.5 & 0.32 \\
\hline kinge & 13.47 & 14.16 & 17.00 & 8.2 & $<0.05$ \\
\hline áne & 9.50 & 9.21 & 9.48 & -1.6 & 0.22 \\
\hline Halland & 8.84 & 10.78 & 11.47 & 7.4 & 0.04 \\
\hline Västra Götaland & 8.96 & 7.98 & 11.04 & 1.4 & 0.55 \\
\hline Värmland & 6.81 & 9.23 & 13.61 & 8.1 & $<0.01$ \\
\hline Örebro & 8.22 & 9.51 & 12.29 & 8.3 & $<0.05$ \\
\hline Västmanland & 9.19 & 10.60 & 11.31 & 4.1 & 0.07 \\
\hline Dalarna & 8.08 & 8.70 & 13.93 & 7.8 & 0.01 \\
\hline Gävleborg & 11.68 & 11.04 & 14.28 & 1.9 & 0.24 \\
\hline Västernorrland & 7.61 & 5.57 & 11.59 & -1.9 & 0.66 \\
\hline Jämtland & 9.74 & 9.80 & 9.85 & 0.0 & 0.99 \\
\hline Västerbotten & 7.39 & 9.36 & 8.94 & 4.0 & 0.06 \\
\hline Norrbotten & 13.60 & 8.34 & 14.24 & -0.6 & 0.86 \\
\hline
\end{tabular}

11.5 per 100,000 women. The increase in the last two years can be seen in all counties except Södermanland, Skåne, Jämtland and Västerbotten. Substantial and statistically significant increases are seen for Östergötland, Jönköping, Blekinge, Halland, Värmland, Örebro and Dalarna, with an average yearly increase of $7 \%-8 \%$. Tendencies of substantial increases are also seen for Uppsala, Gotland, Västmanland and Västerbotten with yearly average increases of $4 \%$ or more."

The above information was gathered from the statistical database managed by the National Board of Health and Welfare in Sweden. The author of the report suggested that it is important to track the causes of the increase in the incidence of cervical cancer. However, no explanations were given for the increase in the incidence of cervical cancer by the NKCX in its 2017 annual report (1).

For analysis, I have sub-grouped the data according to age, 
using the statistical database of the National Board of Health and Welfare (the same database used in reference [1]). In addition, the relevant literature was surveyed to put the current data in perspective.

\section{Results}

The increase in the incidence of cervical cancer was shown to be most prominent among women 20-49 years of age while no apparent increase was observed among women above 50 (Figure 1). The number of cases in the 20-49-year group increased from 202 cases in 2006 to 317 cases in 2015 (an increase of 50\%). In 2015, there were 1.9 million women in Sweden between 20-49 years of age according to Statistics Sweden (2). The incidence of cervical cancer is therefore $0.17 \%$ for women in the 20-49-year group (317 cases per 1.9 million women). Figure 2 shows the relative change between 2006 and 2015 for each 10-year age group cohort, which illustrates the more pronounced increase in the incidence of cancer among the younger age groups.

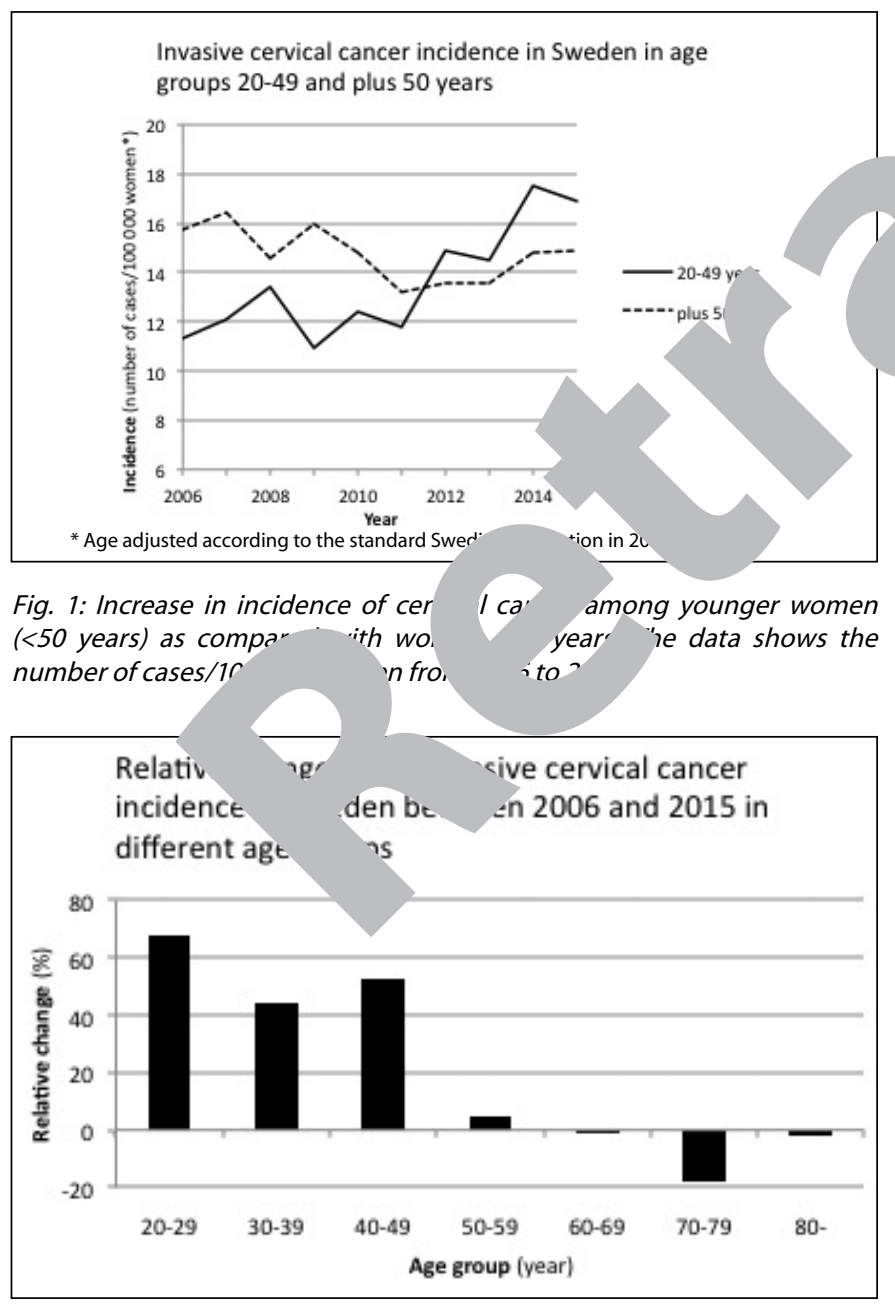

Fig. 2: The relative change in percentage of invasive cervical cancer incidence in Sweden between 2006 and 2015 in different age groups. The figure is based on data from the statistical database of the National Board of Health and Welfare in Sweden. The incidence of cancer is age-adjusted according to the standard Swedish population in 2000.

\section{Discussion}

I discuss below some possible explanations for the increase in the incidence of cervical cancer among young women in Sweden.

A change in the routine or other technical or methodological changes during the study period may affect the reported incidence of cervical cancer due to changes in the sensitivity of the diagnostic tools. The reported change in the incidence among younger women and fact that the increase was noted in most counties in 'en argue against this explanation. Neither was such an a ation given by the NKCx in Sweden in its annual rer with data up to 2016 (1). Recently, when the? dish $\mathrm{m}_{\mathrm{i}}$ liscussed the increase in the incidence of cer cancer, wth authorities were unable to explain th reas

Another possibility is at $\mathrm{H}^{\prime}$ accination could play a role in the increas in the ir of ical cancer. About $25 \%$ of cervical $c$ ave , $i$ of about 3 years including progressio' normaı …s to cancer $(3,4)$. Therefore, an increas may $x \quad n$. thin a short period of time. Gardasil was oved in _ in 2006. In 2010, the vaccination of a s antial number of girls started. In 2010, about $80 \%$ of the ear-ol irls were vaccinated. Combined with $59 \%$ of th ar-old girls vaccinated through the catch-up ramme in the same period, one can say that most girls $v$ ccinated. Thus, the oldest girls in the programme were 23 . rs old in 2015; and this is well within the younger age up shown in Fig. 1. For the older age group represented In Fig. 1, data on exposure to vaccinations is not available. In 2012-2013, most young girls were vaccinated.

The vaccine does not need to initiate the cancer process. There is a possibility of the vaccine acting as a facilitator in an ongoing cancer process. I discuss below some possible mechanisms of how the vaccine might influence the incidence of cervical cancer.

The efficacy of HPV-vaccines has been evaluated by studying premalignant cell changes in the cervix called $\mathrm{CIN} 2 / 3$ and cervical adenocarcinoma in situ or worse (5). The efficacy was calculated for individuals who have not been exposed to HPV 16 and 18. These individuals are called naïve. The vaccine is efficacious only in individuals not previously exposed to HPV 16 and 18 (naïve individuals). If an individual has already been exposed to HPV 16 and 18, no new antibodies are made. Therefore, the vaccine will not work for non-naïve individuals. HPV 16 and 18 are responsible for about $70 \%$ of all cervical cancers (5). It is therefore crucial to give the vaccine to naïve individuals. During their review of Gardasil by the FDA, the efficacy of the vaccine was also evaluated on individuals who were exposed to the oncogenic HPV strains before vaccination since individuals who are non-naïve will also receive the vaccination. A concern was raised for disease enhancement (increase in CIN 2/3, cervical adenocarcinoma in situ or worse) in this subgroup (5). In these individuals, the efficacy was $-25.8 \%$ (95\% Cl: $-76.4,10.1 \%)(5)$. Thus, vaccination with Gardasil 
of non-naïve individuals who had HPV 16/18 oncogenes before vaccination showed a higher level of premalignant cell changes than did placebo. The FDA statisticians could not draw any firm conclusions. In their analysis, the FDA included only cases with HPV 16/18. If cases with oncogenes other than HPV $16 / 18$ had been included in the analysis, the efficacy of data could have been even more unfavourable.

The increase in premalignant cell changes in non-naïve individuals, as suggested by the FDA, is consistent with the knowledge that vaccination can cause reactivation of both target and non-target viruses (6-12). For Gardasil, the HPV types 16 and 18 are called target HPVs since the vaccine contains antigens for these two HPV types. Other HPV types for which the vaccine does not contain any antigens are called non-target HPVs. For individuals exposed to Gardasil, evidence of a selective and significant reactivation of the oncogenic non-target HPV types 52 and 56 was reported in the genital tract for all women (13). This article studied women 13-22 and 23-40 years of age from 2008 to 2013. The target HPVs 16 and 18 decreased only in the younger age group but oncogenic non-target HPVs increased in both the groups, $20 \%-40 \%$ and $8 \%-30 \%$, respectively. The increase in the total burden of non-target oncogenic HPVs for vaccinated individuals may be consistent with the findings in the FDA report where the efficacy of the HPV vaccine was less favourable fo naïve women compared with those on placebo. A mechanism to explain the increased incidence cancer may therefore be virus reactivation as de 'red a'

In the evaluation of Gardasil by the FDA, about $25 \%$ of all individuals were $r-r$ 'e in (5). There are more than 200 type. PVs, of found ivotal trial (14). Hr $\checkmark$ may be found in non-sexually active $\cdots$ (15). I transmitted through non-sexual mean we way o, nother to child, from contact with infec it, from self-inoculation or hospital-acar tior or vi $\operatorname{sod}(17,18)$. The virus can lie la in ar. sue a. detection by standard techniq 19). It also be redistributed systemically during the vious virus-free tissues (autoinoculation), th mple inıcting an earlier virus-free cervix. Recently, it was that previously HPV-positive women with normal cytolc remained at increased risk of preneoplasia (CIN3) despite two follow-up HPV-negative tests (20). "Proving that HPV is absolutely gone is, of course, impossible," state Brown and Weaver in an editorial in 2013 (21). Therefore, non-naïve-individuals can be seen among females at all ages. Sometimes these individuals have measurable HPV and sometimes not. When taking these results into account, the proportion of non-naïve individuals may be underestimated in the studies.

Since the vaccine is recommended for up to 45 years in the European Economic Area, it is possible that the vaccination has facilitated the development of new or existing cervical cancer among women who were non-naïve at the time of vaccination. Vaccination against HPV has started in Sweden during the study period. Gardasil, the vaccine mostly used in Sweden, was approved in September 2006. There are no statistics for the overall use of Gardasil in Sweden. For young girls (12-13 years of age) there are special programmes for vaccination. About $75 \%-80 \%$ of all girls are vaccinated in this age group (22). For older girls there are catch-up programmes. For older girls/women who will be vaccinated on-demand, data on frequency of vaccination are missing. The increase in the incidence of cervical cancer between 2006 and 2015 was $50 \%$ (corresponding to 15 absolute cases). Therefore, the vaccination coverage o. Swedish population does not need to be very high to exp. role for the vaccine. The findings could be consisten ${ }^{+}$mand vaccination of women above 18. In Swedt lere wh ?,946 cervical cell screenings performed on wc aged - J years in 2016 (1). Could the HPV , increase in invasive cervical cancer ir ad eventing it among already infected female and the plai he increase in the incidence of ca orte KCx in Sweden? The increased incider rong yum...y females, the possibility of virus rea ivacio, r. cination, the increase in premalignant cnanges s sy the FDA for women who were already osed to oncogenic HPV types and the time relationship

veen $t^{\prime}$ start of vaccination and the increase in cervical veden could support this view. The answer to this questiun is vital for correctly estimating the benefit-risk of ¿ vaccine. More studies focused on already HPV-infected ılviduals are needed to solve this question.

\section{Conflict of interest: None declared.}

\section{References}

1. Nationellt Kvalitetsregister för Cervixcancerprevention (NKCx), Center för Cervixcancerprevention [cited 2018 Mar 22]. Available from: http:// nkcx.se/templates/_rsrapport_2017.pdf [Swedish]

2. Statistics Sweden [cited 2018 Mar 22]. Available from: http://www. statistikdatabasen.scb.se/pxweb/sv/ssd/START__BE__BE0101__ BE0101 A/BefolkningR1860/?rxid=f45f90b6-7345-4877-ba259b43e6c6e299

3. Bain RW, Crocker DW. Rapid onset of cervical cancer in an upper socioeconomic group. Am J Obstet Gynecol. 1983;146(4):366-71.

4. Hildesheim A, Hadjimichael O, Schwartz PE, Wheeler CM, Barnes W, Lowell DM, Willett J, Schiffman M. Risk factors for rapid-onset cervical cancer. Am J Obstet Gynecol. 1999;180(3 Pt 1):571-7.

5. FDA Gardasil Clinical Review 2006[cited 2018 Mar 22]. Available from; http://www.impfkritik.de/download/gardasil_fda_464_pages.pdf (pp. 359-360)

6. Walter R, Hartmann K, Fleisch F, Reinhart WH, Kuhn M. Reactivation of herpesvirus infections after vaccinations Lancet. 1999;353(9155):810.

7. Bayas JM, González-Álvarez R, Guinovart C. Herpes zoster after yellow fever vaccination. J Travel Med. 2007;14(1):65-6.

8. Rothova A, de Groot JD, Mudrikova T. Reactivation of acute retinal necrosis after flu H1N1 vaccination. Br J Ophthalmol. 2011;95(2):291. doi: 10.1136/bjo.2010.185983. Epub 2010 Aug 23.

9. Hwang CW Jr, Steigleman WA, Saucedo-Sanchez E, Tuli SS. Reactivation of herpes zoster keratitis in an adult after varicella zoster vaccination. Cornea. 2013 Apr;32(4):508-9. doi: 10.1097/ICO.0b013e318277acae.

10. Hassman LM, DiLoreto Jr DA. Immunologic factors may play a role in herpes simplex virus 1 reactivation in the brain and retina after influenza vaccination. IDCases. 2016 Sep 22;6:47-51. eCollection 2016.

11. Jastrzebski A, Brownstein S, Ziai S, Saleh S, Lam K, Jackson WB. Reactivation of herpes zoster keratitis with corneal perforation after zoster vaccination. Cornea. 2017 Jun;36(6):740-2. doi: 10.1097/ 
ICO.0000000000001203.

12. Lieberman A, Curtis L. HSV2 reactivation and myelitis following influenza vaccination. Hum Vaccin Immunother. 2017 Mar 4;13(3):572-3. doi: 10.1080/21645515.2016.1235105.

13. Söderlund-Strand A, Uhnoo I, Dillner J. Change in population prevalences of human papillomavirus after initiation of vaccination:The high-throughput HPV monitoring study. Cancer Epidemiol Biomarkers Prev. 2014 Dec;23(12):2757-64. doi: 10.1158/1055-9965.EPI-14-0687. Epub 2014 Nov 7.

14. Human papillomavirus vaccines. WHO position paper, May 2017 [cited 2018 Mar 22]. Available from: http://www.who.int/wer

15. Hamsikova E, Smahelova J, Ludvikova V, Salakova M, Rychla J, Skrenkova J, Rob L, Tachezy R. The prevalence of HPV infections in HPV-vaccinated women from the general population. APMIS. 2017 Jun;125(6):585-95. doi: 10.1111/apm.12677. Epub 2017 Mar 15.

16. Ryndock EJ, Meyers C. A risk for non-sexual transmission of human papillomavirus? Expert Rev Anti Infect Ther. 2014 Oct;12(10):1165-70.doi: 10.1586/14787210.2014.959497.

17. Bodaghi S, Wood LV, Roby G, Ryder C, Steinberg SM, Zheng ZM. Could human papillomaviruses be spread through blood? J Clin Microbiol.
2005:43(11):5428-34.

18. Chen AC, Keleher A, Kedda MA, Spurdle AB, McMillan NA, Antonsson A. Human papillomavirus DNA detected in peripheral blood samples from healthy Australian male blood donors.J Med Virol.2009 Oct;81(10):17926. doi: 10.1002/jmv.21592.

19. Freitas AC, Mariz FC, Silva MA, Jesus AL. Human papillomavirus vertical transmission: review of current data. Clin Infect Dis. 2013 May;56(10):1451-6. doi: 10.1093/cid/cit066. Epub 2013 Feb 7.

20. Polman NJ, Veldhuijzen NJ, Heideman DAM, Snijders PJF, Meijer CJLM, Berkhof J. HPV-positive women with normal cytology remain at increased risk of CIN3 after a negative repeat HPV test. Br J Cancer. 2017 Nov 7;117(10):1557-61. doi:10.103' $\quad$ 017.309. Epub 2017 Sep 7.

21. Brown DR, Weaver B. Human papı. us in older women: new infection or reactivation? J Infect Dis. _ \ 15;207(2):211-12. doi: 10.1093/infdis/jis662. Epub 2012 Der

22. The Public Health Agency of Swedt ied 20, ?]. Available from https://www.folkhalsomyndighet 'folkhalsc cering-statistik/ statistikdatabaser-och-visualiserin inatir tatistik/statistik-forhpv-vaccinationer/

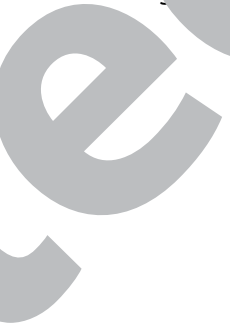

